\title{
IMPROVING ENVELOPE THERMAL INSULATION IN CONSTRUCTION PROJECTS USING NANOTECHNOLOGY APPLICATIONS
}

\author{
Sherif Attallah ${ }^{1}$, Bakhtiyor Khafizof ${ }^{2}$, Jim Jones $^{3}$, Tarek Mahfouz ${ }^{4}$ \\ ${ }^{1}$ Assistant Professor, School of Applied Science and Technology, Ball State University, Indiana, USA \\ ${ }^{2}$ Research Assistant, School of Applied Science and Technology, Ball State University, Indiana, USA \\ ${ }^{3}$ Associate Professor, School of Applied Science and Technology, Ball State University, Indiana, USA \\ ${ }^{4}$ Associate Professor, School of Applied Science and Technology, Ball State University, Indiana, USA
}

\begin{abstract}
Conservation of energy consumption in the construction industry is becoming more important than ever due to global issues related to the increased energy demand. Energy consumption in heating and cooling systemsfor commercial and residential buildings is a major portion of the overall energy consumption. One important approach to respond to this type of consumption is to enhance the thermal resistance ( $R$ value) of building envelopes with a special focus on the insulation materials. Nanotechnology as an emergent science and engineering field is developing solutions to enhance the resistance value of different building products withinnovative methodsincluding, reducing the pore size of insulation materials. This paper presents a review of utilization of nano-enabled products to improve insulation materials. The research involves exploring the literatures that cover area of technology application in addition to the commercial products currently being offered in the construction market. Findings indicate that the relatively high cost of the nano-products is due to lack of both mass production and familiarity of public to these products.
\end{abstract}

Key Words: Thermal Insulation, Nano Insulation, Envelope, Heat Resistance, Construction Projects.

\section{INTRODUCTION}

The construction industry is responsible for widespread resource consumption and harmful emissions to the environment due to the diversity of multiple supply chains leading to the final product and anextensivelifetime of buildings, As stated by Environmental Protection Agency (EPA), buildings are accountable for $38.9 \%$ of total U.S. energy consumption in 2005 [1]. Out of the entire energy utilization, in an average household, $50 \%$ of the consumed energy is spent onspace heating, 27\% goes for appliances, $19 \%$ to water heating and $4 \%$ for air conditioning[1]. This indicates that heating and cooling systems account for the majority of household energy use in the United States.One of the most efficient and easiest ways to reduce energy usage is to decrease the load on heating and coolingsystems by decreasing the amount of heat escaping (winter)or coming in (summer) through the envelopesof the buildings. Increasing the thermal resistance ( $R$ value) of different materials forming the composite of the envelopes, mainly in the envelopes of external walls and roofs, is a major factor to achieve this objective. Conventionally, materials such as, rock wool, glass wool, urethane foam, polystyrene,vermiculite, plant fiber (cannabis, flax, cotton, cork, etc.), recycled cotton denim, cellulose, wood fiber,plant straw, perlite, animal fiber (sheep's wool), cement, and even soilare used as insulation materials toincrease the thermal resistance ( $\mathrm{R}$ values). All of these materials have a degree of thermal resistance and other beneficial characteristics that makes them suitable as insulation materials.

These traditional materials are being used for many decades if not centuries.However, emerging fields like nanotechnology are paving their way into the market and introducinginsulationsmaterials that can be far more efficient, non-toxic, low odor and environmentally friendly [2]. Therefore, professionalsin the construction industry are exploringthe usage ofNano-property materials as an effort to reduce the transfer of heat through the building envelopes. Nano insulation products are being produced in the form of coatings, paints, and thin films[3]. This paper represents an effort to review developmentsand applications of nanoenabled materials that are being introduced as envelope thermal insulation inthe American and European markets. Furthermore, the paper examinessome of the challenges facing deployment of nanotechnology in this important segment of theconstruction industry.

\section{ENVELOPE INSULATION}

The effectiveness of an insulating material is measured in terms of its thermal resistance or R-value. The higher the Rvalue, the less the heat transferred through the envelope. The high R-values, therefore,providebetter control of internal comfort in sever hot and cold conditions. The R-value can depend on the type, density and thickness of the different materials composing the building envelopes[4]. One of the 
most cost-efficient ways to increase resistance is to add additional insulation material to the envelope because the insulation layer in any envelope composite section has the maximum contribution of the overall R-value. Properly insulated buildings cannot only reduce the heating and cooling costs, but also improve the comfort level within the buildings[5]. In order to improve our understanding of insulation we have to analyze heat flow and identify how it works[6]. There are three elementary mechanisms: conduction, convection, and radiation.

Conduction is the movement of energy in the form of heat by microscopic diffusion and collisions of atomic particles with one another within an object and among different objects [7]. In the simplest definition, conduction is the way heat shifts within materials. Generally, the heat shifts from a hotter to a colder object, and temperature differences decline over a period of time where the bodies of the objects approach thermal equilibrium [6]. Conduction occurs in solids, liquids and gases. However, solids can transmit energy more efficiently than liquids and gasses, since the molecules in solids are tightly packed or placed close to one another. For liquids and gases, the density of the particles is generally lower and molecules are placed away from each other, making them less efficient [8]. Convection is the movement ofheat by mass motion of a fluid such as air or water [6]. The heated fluid causes molecules to move away from the source of heat, moving energy with it to the colder bodies. Thus,less dense material rises and colder denser materialsinks, which ultimately results in transfer of heat [6]. In other words, convection is the means that heat flowsor circulates through a medium, which could be a liquid or a gas. Radiant heat proceedsin a straight line in waveform and heats bodiesin its pathway [9].

Most of the insulation materials in the envelope work by slowing conductive and convective heat flow process. Radiant barriers and reflective insulation materials reduce radiant heat gain. The barriers comprised of highly reflective elements, reboundson coming heat rather than absorbing it. However, these barriers do not have the same capability of reducing heat conduction compared to thermal insulation materials [10]. To maintain a comfortable temperature in the building, the gained heat must be removed by cooling systemsand loss of heat must be compensated for by heating systems. Therefore, properly insulated buildings create comfortable living environment. In addition, it reduces the load on heating and cooling equipmentby maintaining a positive resistance to the flow of heat [11].

\section{NANO TECHNOLOGY FOR INSULATION OF BUILDINGS}

There are several ways in which thermal resistance of insulation in building envelopes can be increased. One way issimply to increase the thickness of insulation within the structure's envelope[12]. This technique can be followed for new buildings in efforts to increase thermal insulation; however it is not feasible if the project is a building renovation neither if there are limitations on usable areas in some projects.In fact, one of the biggestobstacles in the construction industry is the thermal renovation of existing residential and industrial buildings [13]. With existing structures, the framework and internal gridlines have been established. Thus, increasing the thickness on insulation will change the dimensions of the structure, altering the framework and boundaries of the building[31]. This alteration would make renovation projects more complicated and costly for the owners. This issue is less critical for new construction projects since the thickness of the envelope can be calculated into the framework of the building, making it a better option for construction management teams[14].

Typically, older structures are the least energy efficient due to deterioration of the condition of the envelope and structure materials. Hence, it is important to find ways in which owners can update the existing insulation in efforts to reduce energy consumption. To achieve this objective, the existing insulation can be replaced with a type of material that has higher thermal resistant [15]. Over the past several years, new superinsulation materials have been developed based on nanotechnology. Such nano-materials made their way to the forefront of research and development of construction industry [16]. As stated by Leydecker, nanomaterials offer extremely durable, prolonged and, at the same time, superlight construction materials, which can be used as effective insulating materials [17].

Nanoscienceis the study of how materials change their physical and chemical properties as they break into extremely small particles at the Nano scale. This definition can be applied across all the other science fields, such as physics,biology, chemistry, materials science and engineering [18]. Nanotechnology involves the ability to see and to control behavior of materials at the level of atoms and molecules, thus manipulating their properties. Today's scientists and engineers are exploring a wide variety of techniques to deliberately create materials at the nano-scale to make use of their enhanced properties [18]. Thus, nanomaterials enhancethe products in many different ways, such as improved strength, lighter weight, advanced light spectrum control, and better chemical reactivitythan their greater-scale counterparts[19].

\section{CONSTRUCTIONNANO-ENABLED PRODUCTS}

Using different potential insulation materials for thermal insulation of envelopes such asVacuum Insulation Materials (VIM), Nano Insulation Materials (NIM), Gas Insulation Materials (GIM), and Dynamic Insulation Materials (DIM) is aiming at improving thermal conductivity of the properties. The main disadvantage of traditional GIM and VIM methods is that their performance deteriorates over time due to intrusion of vapor and air into the gas or vacuum filled pores. This makes the conductivity increases with time and therefore it results in increase in energy consumption. The Nano Insulation Materials (NIM) addresses this issue where the size of pores is below $40 \mathrm{~nm}$ reducing the probability of penetration of vapor. 
The Knudsen effect is described in Chemistry and Physics references as an indication of the relationship between the pore size and the thermal conductivity of the air pores. Figure 1 ispresented by Jelle et al.as a representation of the empirical equation that links both properties. The graph shows that the lower the pore size is, the lower the thermal conductivity and therefore the higher the thermal resistance is [20]. According to Jell et al. this relationship represents the conduction in heat transfer only, since the convection in heat transfer (resulting from movement of air inside the tiny pores) is considered very minimal [20]. The third type of heat transfer isradiative heat transfer, follows a trend similar to the conductive heat transfer as represented in Figure 1.

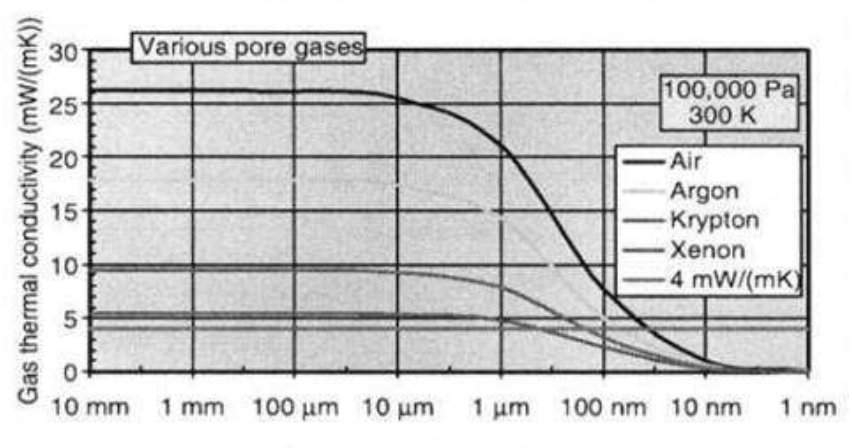

Characteristic pore diameter

Figure 1: Relationship between pore size and thermal conductivity

In the lastfew decades, the nanotechnology has transformed several sectorsand industries including, science, engineering, construction and commercial [21]. The application of nanotechnology improvescertain components of building materials transforming them to become superstrong structuralmaterials, self-cleaning façades, smart windows, and advanced thermal insulation materials [22]. Nano insulation materials (NIMs) are offered as homogeneous materials with a closed or open nano-porous structure. These NIMs have thermal conductivity of less than $0.004 \mathrm{~W} /(\mathrm{mK})$ in the original condition [22], which makes them anappealing alternative for any applications. Current applications are in the forms of coatings, paints, and thin films or as solid materials.

There are a few different types of NIMs. One example of products based on nanotechnology is aerogel, which is an advanced material that holds unique properties including extremely low-density and super insulation. Aerogel is a silica-based materialcomprised of a loose network of silicon atoms, which is produced by extracting the liquid from a silica alcogel and exchanging it with air. Air makes up 99.8 percent of the final product. Some aerogels hold density as low as 0.0005 ounces per cubic inch. Aerogels are good thermal insulators due to their capability of almost nullifying the three methods of heat transfer (convection, conduction and radiation).According to Shukla et al., the resulting nano-porous structure of the aerogel leads to a considerably higher thermal resistivity value of around 69 $\mathrm{mK} / \mathrm{Wcompared}$ to the commonly used plastic foams [23].
Originally, aerogel was produced for National Aeronautics and Space Administration (NASA) to use in the space suits worn by astronauts. Aerogel is nonflammable, non-toxic, lightweight, and water resistant, which all are highly preferable properties for creating a thermal insulating material. Aerogel applications in building enclosures are fast growing. In addition, other building applications, such as incurtain walls, window panels, and local insulation around windows and steel frames to ease thermal bridging have now been actively pursued [23].Considering, low production volumes and excessive production costs, aerogels are currently costlier than the conventional building insulation materials. Several aerogel-based building products in the form of thermal-insulating blankets and high-performance windows have been commercialized in the US, and the production volume for aerogel is increasing.

Thermablock is a product that is made from aerogel. The product is used in residential and commercial applications. The strips of Thermablock are used to cover studs in envelopes. It allows minimizing the thermal bridging caused by the difference in conductivity between the used insulation and the wooden or metal studs. It can also be used as a replacement for the insulation materials providing $\mathrm{R}$ value of 10 and it's usually supplied in 1/4and $3 / 8$ of an inch.

Another similar product iscalled Nansulate ${ }^{\circledR}$ Home Protect. Nansulate ${ }^{\circledR}$ Home Protect is a coating, patented by Industrial Nanotech, Inc., which utilizes a Nano composite with an exceptionally low thermal conductivity and nanomaterial properties. This material is marketed as a coating which effectively conceal heat transfer inextremely thin covers [24].Nansulate ${ }^{2}$,similar to Aerogel,is a nontoxic, non-flammable, low odor and environmentally friendly product, however the product is water based. The product can be used for walls, ceiling, attics, interior or exterior, ductwork, skylights, trailers/RVs and pet enclosures. The advantage of this NIM is that it is an excellent thermal insulation product, with high resistant to growth of mold and mildew. It is highly moisture resistant, vapor impermeable and UV resistant. Thus, it protects surfaces from weathering and different environmental damages. Test results from independent laboratory examining Nansulate ${ }^{\circledR}$ Home Protect coating material, indicates that thermal flow through the portion coated with Nansulate $\AA$ was reduced by $34.80 \%$ and thermal resistance $(1 / \mathrm{U})$ of the wall was increased by $28.98 \%$ [24]. Nansulate ( be directly applied to the walls of olderor newer buildings without necessitating any post-construction addition. As a super product,Nansulate ${ }^{\circledR}$ is reported to provideperformance qualities of strong thermal insulator and corrosion preventer. Gammampila et al. reported that Nansulate is a product of nanotechnology that reduces the operational energy usage of the buildings to a great extent [13].

The third widely available thermal insulation product is NanoPore $^{\mathrm{TM}}$ Thermal Insulation. NanoPore ${ }^{\mathrm{TM}}$ Thermal 
Insulation is anabsorbent solid that provideslow density with small pores. Its chemical structure consists of silica, titania and/or carbon in a 3-D. The material contains pore sizes ranging from 10-100 nm [25]. Due to its excellent pore formation,NanoPore ${ }^{\mathrm{TM}}$ Thermal Insulation delivers resistance as high as R40/inch, which is 7 to 8 times higher than traditional foam insulation material [25].The conductivity of the material is lower than air at the equal pressure. Gas particles within the matrix experience diffusion, which exhibits the Knudsen effect [26]. NanoPore ${ }^{\mathrm{TM}}$ ThermalInsulation material can be utilized over a wide range of temperatures, such as below cryogenic (<$\left.196{ }^{\circ} \mathrm{C}\right)$ to high temperatures $\left(>800^{\circ} \mathrm{C}\right)$ [25]. The product is being produced in different grades to meet diversegroups of projects and special needs.

Firms such as Kingspanare in the business of producing variety of envelope systems offering many different insulated materials based on nanotechnology, which are widely used in the construction industry. The firm offers durable insulated wall panels with superior R-value, highenergy efficiencyensuring stable interior environment [27]. Kingspan offersdifferent variety of nanomaterial wall panels that have unique features. The first products that have similar features are called 200 Inverted Riband 300 Minor $R i b$, which are insulated metal panelsthat can be used in various compositions for both vertical and horizontal surface applications. The products aredelivered as a single part metal panels, reducing construction delays, labor costs, and generatingquicker on-site installation comparing to multipart wall systems. The panelsare claimed to provideexcellent resistance value with strong airtightness and low thermal bridging leading to energy conservation of as much as $30 \%$ over the traditional systems [27]. Alternatively, 300 A Azteco ${ }^{\circledR}$ Embossed foam insulated panels are flexible in structure and can be utilizedfor various design applications.According to Kingspan, it increases energy efficiency by above $30 \%$ over multipart built-up systems. These products are also a single component insulated metal panel products, which makes them quick and easy to install. There are many different products such as: 300 R Striated, 300 GS Ganitstone ${ }^{\circledR}, 400$ V-Wavem, Mini Wave, Shadowline and many others that have similar features with different texture and design [27].

In addition, DryWired, a firm based in Los Angeles, California, is in the business of producing and distributing advanced surface nanotechnologies globally. The firm aims to provide eco-friendly protective thin-film coatings making buildings more energy efficient, surfaces cleaner while reducing wastes [28]. That being said, theNano products used in thermal insulation of buildings are called Heat Shield Smart Paint (HSSP). Heat Shield Smart Paint is marketed as a high performance protective coating for thermal insulation that significantlycondenses thermal transmission on any hard surface. In addition to that, HSSP's adhesion and water barrier qualities are claimed to be far greaterthan conventional paints [28]. It can be applied on walls, ceilings, attics, interior or exterior and ductwork and delivers UV fade protection withbarriers built in to prevent algae,mildewandmold[28].

A Proctor Group is another firm supplying "super" insulation products. The firm produces an ultra-thin material for thermal insulations called Spacetherm. The material comes on its own and/ or layered to a number of facings to meet customer's requirements and needs. The product provides a high thermal resistance due to its structure and usage of flexible aerogel blankets [29]. The material used in Spacethermisdeveloped from silica gel and it offers a $\mathrm{K}$ factor of $0.014 \mathrm{~W} / \mathrm{mK}$.Spacethermis claimed to providereliable thermal performance over the course of 50year product's lifetime and similar to HSSP, it also offers resistance to mold growth and algae. The material isalso claimed to be eco-friendly withzero ozone depletion [29].

\section{MARKET STATUS}

Over years, the National Science Foundation (NSF) has promoted cross-disciplinary nanoscience and engineering developments, which led toa global growth of nanotechnology as an industry [30]. Lux Research Group published a report on global spending innanotechnologyand innovativenano-enabled products. The reportstates a 40percent increase in global funding for the advancement of nanotechnology. Additionally, revenue from Nano-enabled products increased worldwide and evenues grew from $\$ 339$ billion in 2010 to $\$ 731$ billion in 2012 and to more than $\$ 1$ trillion in 2013 [30]. Revenue from the United States only was $\$ 110$ billion in 2010, \$236 billion in 2012 and $\$ 318$ billion in 2013 [30]. It is estimated that by the end of 2018 the global nanotechnology market would reach $\$ 4.4$ trillion [30]. These numbers show a vast demand for Nano-material products and investments in research and development of nanotechnology in US and globally. However, these numbers are for applications of nano-materials in general while numbers related to market value for thermal insulation of envelopes using nanotechnology are still insignificant due to high initial cost of these materials compared to traditional insulations types.

When introducing a new material to the market, it is vital not only to look at the physical properties of the material, but also analyze the means of manufacturing and recycling of the materialto ensure no rebound effects occur when shifting to more efficient products[31].In this context, Nanotechnology opens up new possibilities with more ecologically oriented, effective and affordable means in engineering industry. Regrettably, the availability of Nanomaterial products for thermal insulation in US market, morespecifically in construction industry, is still rare. Nanomaterial thermal insulation products are still in the stages of research and development. Therefore, there is limited number of Nano-material products such as Thermablock, Nansulate ${ }^{\circledR}$ and NanoPore ${ }^{\mathrm{TM}}$ that are available to be usedfor heat resistance and thermal insulation. These products are yet to be mass-produced due to high production costs [17].Thus currently, Nano-materials are still significantly more expensive than the traditional materials [13].Furthermore, using Nano-material products with lack of practical experience and knowledge by contractors can be 
very costly and time consuming [17]. Consequently, the construction industry currently relies on proven and experimented products that have demonstrated positive results. At present time, our state of knowledge and awareness of Nano-technology applications and products are still somewhat limited regarding the availability of the products in the market and their performance in the construction industry [24].

In 2009, a survey wereheld in the construction industry, which indicatedthat almost $75 \%$ of the respondents were unaware of whether or not they were working with "Nanoproducts" [13]. The lack of awareness of the respondents is partially due to the fact that there are no legislativerequirements for labeling of nanomaterial products in construction materials [17].This is another issue that needs to be resolved in the near future, so the users of these types of products would be aware of the material content and their characteristics.

\section{DISCUSSION \& CONCLUSION}

The research workon the use of Nano-technology forimprovement of thermal resistance ofthe building envelopes is still limited. Previous studies andinvestigationsindicates that nano-products in the construction industry continues to have a secondary role. Therefore, nano-productshold a very small percentage of the construction market. On the other hand, it is vital to mention that the construction market is considered to be conservative market, where innovations more often face difficulties entering the market [32].

In conclusion, in this paper,nano-enabled materials are investigated asdifferent meansof achieving higher thermal resistance for building envelopes. Nano-enabled materials offer extremely low thermal conductivity, with zero emission and eco-friendly alternative. The conventional means of insulation are still being highly used due to high cost production of Nano insulation materials. However, the gradual increase in investment and interests from governments, corporations and private parties on nano products are expected to help finding means of decreasing productions costs and providing other alternative solutions. Even though experienceof using Nano-technology as a means to increase thermal resistance is still limited, the potential of Nano-technology is promising. After careful research and study of Nano-material products we recommend to further study the financial feasibility and awareness of the public related to Nano-material products.

\section{REFERENCES}

[1] Green Building (2009). In Environmental Protection Agency. Retrieved October 2, 2015, from http://archive.epa.gov/greenbuilding/web/html/about.ht $\underline{\mathrm{ml}}$

[2] Dowson, M.; Harrison, D.; \&Dehouche, Z. (2015). Trombe walls with aerogel insulation applied to UK housing refurbishments. International Journal of Smart and Nano Materials, vol. 5(4), 283-303.
[3] Gao, T., Jelle, B. P., Sandberg, L. I. C., \&Gustavsen, A. (2013). Monodisperse hollow silica nanospheres for nanoinsulation materials: Synthesis, characterization, and life cycle assessment. ACS applied materials \& interfaces, 5(3), 761-767.

[4] Melo, A. P., \& Lamberts, R. (2009, July). Envelope insulation and heat balance in commercial buildings. In Eleventh International IBPSA Conference (Vol. 2, pp.7-30).

https://www.nsf.gov/news/news_summ.jsp?cntn_id=13 $\underline{0586}$

[5] Bachmann, A., \&imDiskurs, E. (2013). Synthetic nanoparticles and the precautionary principle An ethical analysis. Resource document. Swiss Federal Ethics Committee on Non-Human Biotechnology. http://www.ekah.admin.ch/fileadmin/ekahdateien/dokumentation/gutachten/e-GutachtenSynthetische-Nanopartikel-2007. pdf. Accessed, 20.

[6] Majeed, K. J. (2013). Improvement of Thermal Conductivity of Nano MgO/Epoxy Composites for Electrical Insulation Materials. AIP Conference Proceedings, 15(69), 304-308.

[7] Ni, Y., Chalopin, Y., \&Volz, S. (2013). Significant thickness dependence of the thermal resistance between few-layer graphenes. Applied Physics Letters, 103(6), 061906.

[8] Sayes, C. M., Rothrock, G. D., Norton, C. A., \& West, C. S. (2013). Life cycle considerations for engineered nanomaterials: A case study for nano-enabled coatings on drywall. In NSTI-Nanotech (Vol. 3,p.742).

[9] Hou, W., Chuang, T., Hsieh, E., \& Chang, Y. (2012). An analysis of heat insulation efficiency of building outer skins used for green building. Building Services Engineering Research \& Technology, 33(4), 407-422.

[10] Sullivan, C. C. (2013). High-performance envelopes: Meeting new energy codes with manufactured systems. Environmental Design \& Construction, 16(6),55-62.

[11]Zheng, M., Sun, S., Hu, J., Zhao , Y., \& Yu, L., (2014). Preparation of Nano-Composite $\mathrm{Ca} 2-\alpha \mathrm{Zn} \alpha(\mathrm{OH}) 4$ with High Thermal Storage Capacity and Improved Recovery of Stored Heat Energy. Open Engineering. 5(1), 42-47.

[12] Frydrych, I., Dziworska, G., \&Bilska, J. (2002). Comparative analysis of the thermal insulation properties of fabrics made of natural and man-made cellulose fibres. Fibres and Textiles in Eastern Europe, 10(4),40-44.

[13] Berevoescu, L., Stoian, V., \& Dan, D. (2009). Aerogela performant Nanomaterial for sustainable buildings. In 11th WSEAS International Conference on Sustainability in Science Engineering (pp. 457-462).

[14] Gammampila, R., Mendis, P., Ngo, T., Aye, L., \&Herath, N. (2013). Application of nano insulation materials in the sustainable Built environment.

[15] Koebel, M., Rigacci, A., \&Achard, P. (2012). Aerogelbased thermal superinsulation: an overview. Journal of sol-gel science and technology, 63(3), 315-339. 
[16] Sabah, D., \&Abd, A. D. A. M. Energy efficiency in sustainable buildings.

[17] Leydecker, Sylvia, 2008, Nanomaterialien in Architektur, Innenarchitektur und Design: BirkhäuserVerlag.

[18] Nanotechnology Update: Corporations Up Their Spending as Revenues for Nano-enabled Products Increase (2014, February 14). In Lux Research. Retrieved September 2, 2015, from https://portal.luxresearchinc.com/research/report_excer $\mathrm{pt} / 16215$

[19] Kosny, J., Petrie, T., Yarbrough, D., Childs, P., Mohiuddin Syed, A., \& Blair, C., (2007). Nano-scale insulation at work: Thermal performance of thermally bridged wood and steel structures insulated with local aerogel insulation. Buildings.

[20] Jelle, B. P., Gustavsen, A., \&Baetens, R. (2010). The path to the high performance thermal building insulation materials and solutions of tomorrow.Journal of Building Physics.

[21] Cui, S., Mattson, E. C., Lu, G., Hirschmugl, C., Gajdardziska-Josifovska, M., \& Chen, J. (2012). Tailoring nanomaterial products through electrode material and oxygen partial pressure in a mini-arc plasma reactor. Journal of Nanoparticle Research, 14(3), 1-13.

[22] Gao, T., Sandberg, L. I. C., Jelle, B. P., \&Gustavsen, A. (2012). Nano insulation materials for energy efficient buildings: a case study on hollow silica nanospheres. Fuelling the Future: Advances in Science and Technologies for Energy Generation, Transmission and Storage, 535-539.

[23] Shukla, N., Fallahi, A., \&Kosny, J. (2014). Aerogel Thermal Insulation--Technology Review and Cost Study for Building Enclosure Applications. ASHRAE Transactions, 120(1), 294-307.

[24] Nanotechnology in Construction (2015). In NanoWerk. Retrieved September 10, 2015.

[25] NanoPore ${ }^{\mathrm{TM}}$ Thermal Insulation (n.d.). In NanoPore. Retrieved September 4, 2015, from http://www.nanopore.com/thermal.html

[26] Passian, A., Warmack, R. J., Wig, A., Farahi, R. H., Meriaudeau, F., Ferrell, T. L., \&Thundat, T. (2003). Observation of Knudsen effect with microcantilevers.Ultramicroscopy, 97(1), 401-406.

[27] Insulated Metal Wall Panels (2015). In Kingspan. Retrieved November 7, 2015, from http://www.kingspanpanels.us/products/commercialindustrial/insulated-metal-wall-panels

[28] DryWired Heat Sheild: Smart Paint (2015). In DryWired. Retrieved November 7, 2015, from https://drywired.com/wpcontent/uploads/2015/06/DryWired-Heat

[29] Spacetherm (n.d.). In A Proctor Group. Retrieved November 7, 2015, from http://www.proctorgroup.com/products/spacetherm

[30] Market report on emerging nanotechnology now available (2014). In National Science Foundation.
Retrieved November 7, 2015, from https://www.nsf.gov/news/news_summ.jsp?cntn_id=1 $\underline{30586}$

[31] Belyakov, A., \&Ivanov, S. (2008). Advantage of heat insulation made of materials with natural porosity. Refractories \& Industrial Ceramics, 49(4), 300-303.

[32] Shield_Smart-Paint-PDS.pdfElguezabal, P., \&Garay, R. (2015). Experiences when employing different alternatives for envelope upgrading. Journal of Facade Design and Engineering, 3(1), 81-89. 